\title{
Preface
}

\section{$T_{h e}$}

Moon in the Water is designed as an introduction to Kawabata, Mishima, and Tanizaki. It is intended not as a work of critical theory but as a practical guide meant to increase the reader's enjoyment by revealing layers of meaning that would not generally be apparent to anyone unfamiliar with Japanese literature.

Readers who can enjoy the works of these three authors in the original will appreciate the difficulties of discussing the fiction on the basis of works available in English. They will also understand that since the following pages are particularly designed to increase the pleasure of readers who do not know Japanese (or who read the literature only slowly and with difficulty), I have tried to stay as close as possible to currently available translations, keeping references to untranslated materials very brief.

To avoid confusing the reader who is not familiar with both languages, I have tried whenever possible to conform to the precise wording (usually enclosed in quotation marks) of available English versions, which are listed in the separate authors' bibliographies, rather than using the phrasing of my own readings, even when I regard the published translation 
as inadequate in minor details. Occasionally, however, I retain my own English versions or substitute more precise wording without indicating such changes. Thus I hope that the reader will be able to enjoy the following pages without the distraction of parenthetical corrections or the confusion of discussions that do not seem to match the available translation precisely. The Japanese language forces the translator to select a precise phrase or detail from a dozen possibilities - often seemingly contradictory, at least to the reader not familiar with Japanese-a fact demonstrated in English discussions of untranslated works and the differences among various versions of a single short story.

The appendix to chapter 1 gives some idea of the range of meanings that three eminent scholars can draw from the Japanese language. The three parallel translations demonstrate the extent to which all the translations under discussion may differ radically from the original Japanese. Because of such inevitable differences, I have not attempted the specialized task of comparing texts and arbitrating disputes here, except when translations may have created a false impression for the reader who lacks firsthand experience of Japanese language, literature, or daily life.

The brief chapter entitled "Contexts" introduces some important names and dates of the historical framework in which modern Japanese writers should be considered. At the same time, it suggests a few of the special qualities of Japanese language and symbolism, recommending helpful collateral readings for anyone who wishes to explore further.

The chronologies give additional information on publication dates (including the intricacies of serial publication whenever possible) to aid readers wishing to make specialized textual studies. I have included some identifying information on content for the reader who does not have access to this Japanese material, as well as a lengthy bibliography for each author's short stories, novels, and other works available in English translation. There is also a general bibliography 
listing additional Japanese authors and anthologies and several useful critical studies.

Dates in these chronologies and bibliographies are sometimes different from those given in other English studies of Japanese literature, and even from the dates of original publication given in the copyright information of translations. A few of the errors I have corrected may have occurred in the course of providing Western equivalents of the Japanese system, in which the reign years "first year of Taishō" and "last year of Meiji" both indicate 1912 while the last year of Taishō and Shōwa One both fall in 1926. Other errors may have resulted from the system formerly used in calculating ages in Japan. A work written "when Tanizaki was twenty-five years old" (between 24 July 1911 and 23 July 1912 by the Western calendar) might well refer to a work completed in 1910.

A more frequent cause of difficulty, however, is the system of serial publication, common in Japan. First publication may have been spread over several years (and even different publications), the work appearing as a book-sometimes under a different title-months or years later. The history of Kawabata's Yukiguni (Snow Country) from the publication of the first installment in January 1935 through "complete" versions in 1937, 1948, and later is an extreme example of the difficulty. Moreover, the various segments-often seemingly "complete" tales-may have appeared under quite different titles and be listed in bibliographies as short stories (a difficulty compounded by the Japanese habit of using shōse$t s u$ as a term for both short story and novel). In this book, with few exceptions, the publication dates of Japanese titles given in text, footnotes, and bibliographies are those of first (often serial) publication. The chronologies provide information on dates of subsequent publication and performance of plays.

A note in Miyoshi's Accomplices of Silence refers to the reliability of Mishima bibliographies but would apply equal- 
ly to the majority of Japanese bibliographies. Therefore, I have given in my chronologies only those dates I could verify by consulting the original publications. These dates have been further checked by three Japanese scholars, to whom I would like to express my profound gratitude. Nevertheless, I fear that we may still have been defeated in our attempted accuracy by some of the factors suggested above.

My extensive footnotes occasionally clarify other points of scholarly dispute and interpret esoteric allusions in terms more appropriate for those who have read the novels in Japanese. The primary purpose of my notes, however, is to increase the general reader's enjoyment by identifying specific ways in which an understanding of Japanese cultural patterns and unfamiliar symbolism can provide added dimensions to the translations. Some of the notes amplify points mentioned only briefly in the general discussion, while others draw the reader's attention to variant interpretations, comparisons, and contrasts.

Apart from added paragraphs referring to the deaths of Mishima and Kawabata, revised sections to reconcile my discussion of the earlier volumes of the untranslated Sea of Fertility with the complete English translation, and added comments on Kawabata's The Lake and Beauty and Sadness, the following pages were completed in the fall of 1970, not long after I had returned to Japan. Various studies have been published since that time, and the list of translations is growing. It has generally not been possible to mention these in my discussions; I have tried, however, to identify the most useful of them in my footnotes.

In my discussions of the authors and their works, I have whenever possible used the phrasing of the many excellent published translations. For permission to quote from these sources as necessary (usually briefly), and to make occasional use of an author's or translator's accompanying notes, I am deeply grateful to the following: Asahi Shimbun (publisher of This is Japan and Japan Quarterly); The Asia Society, Inc.; 
The Atlantic Monthly; Columbia University Press; The East Publications, Inc.; Hokuseidō Press; Alfred A. Knopf, Inc.; and Charles E. Tuttle, Co., Inc.

It is impossible for me to thank adequately and by name all those whose kindness and patience contributed in various ways to this book. I should like, however, to express my profound gratitude to the scholar-friends in Japan who helped me unravel knotty questions of syntax and symbolism when we discussed the first draft of my manuscript. I should also like to thank the friends who introduced me to the pleasures of living in Japan-taking me behind the scenes at the Kabuki, to student performances of Mishima's modern Nō plays, and to recitals of classical music and dancing; or introducing me to their professional worlds of medicine, filmmaking, and Kyoto's geisha and maiko during ten delightful years.

The Moon in the Water has been a labor of love. I have not been supported by grants or academic institutions during its preparation, but completed it with the encouragement of my colleagues and students in Japan and California. And I have saved until last a very special thank you to those who shared their homes with me and welcomed me in settings that were often far from my scholarly world-settings as different as a barge in the port of Kobe, a castle of great beauty, and the living quarters of one of Nara's temples, a center of Zen Buddhism. 